\title{
A ARGUMENTAÇÃO EM SALA DE AULA - O ENSINO DO ARTIGO DE OPINIÃO NOS APOSTILADOS DA REDE PÚBLICA PAULISTA
}

\author{
Sílvia Mamede de CARVALHO \\ (Universidade de São Paulo) \\ silviamamede@bol.com.br
}

\begin{abstract}
Resumo: Neste artigo, pretendemos demonstrar parte dos resultados obtidos em dissertação de mestrado defendida em 2015, pelo programa de Mestrado Profissional em Letras (PROFLETRAS), na qual tratamos de questões voltadas ao ensino do gênero artigo de opinião no $9^{\circ}$ ano do Ensino Fundamental. Nosso objetivo é conhecer e explicitar de que modo os alunos são orientados quanto à aprendizagem desse gênero. Para tal fim, procedemos à análise do Currículo Oficial de Língua Portuguesa, adotado nas escolas da rede estadual de ensino do Estado de São Paulo, além de descrevermos e analisarmos as atividades propostas para a aprendizagem do artigo de opinião, contidas no apostilado "Caderno do Aluno". Como resultado, observamos um distanciamento entre o que está prescrito no Currículo de Língua Portuguesa e as atividades propostas aos alunos para a aprendizagem do artigo de opinião. Verificamos, ainda, na Situação de Aprendizagem analisada, que os encaminhamentos propostos para o ensino da produção textual desse gênero discursivo não possibilitam que os alunos vivenciem a escrita argumentativa como prática social significativa.
\end{abstract}

Palavras-chave: Produção escrita. Argumentação. Artigo de opinião. Apostilados.

\section{ARGUMENTATION IN THE CLASSROOM -TEACHING OPINION ARTICLES IN STUDENT'S BOOKLETS PRODUCED BY THE PUBLIC SECTOR IN SÃO PAULO.}

Abstract: In this article, we intend to show part of the results of a study developed in order to get a Master's degree, having the thesis been defended in 2015. Itdeals with issues related to the teaching of opinion articles in the $9^{\text {th }}$ grade of Elementary Schools. It aims at becoming familiar with and rendering explicit the way in which students are oriented according to the official document regarding the learning of this genre. In order to achieve such a goal, the Portuguese Language Curriculum, which is followed by the schools run by the State Government of São Paulo as well as the activities proposed in the Caderno do Aluno (Students' Booklet) were analyzed. The results obtained suggest that there is a gap between what is prescribed by the Portuguese Language Curriculum and the activities aiming at the learning of opinion articles. It was observed that the Learning Situations analyzed do not contribute to 
the meaningful learning of that genre, since the practices do not allow students to experience argumentative writing as a meaningful social practice.

Keywords:Writtenproduction. Argumentation. Opinionarticle. Booklets.

\section{Introdução}

Sabemos que para uma real participação e compreensão social, é fundamental dominar e conhecer a função dos diversos textos que circulam na sociedade e esse conhecimento constitui um dos principais papéis da escola, sobretudo dos professores de língua materna. Não basta apenas reconhecer a qual gênero pertence um determinado texto, sua estrutura e características principais; é necessário que se compreenda a função dos textos nos diversos momentos de sua vida e saiba selecionar e adequar os gêneros do discurso e a linguagem a cada situação comunicativa.

Segundo os Parâmetros Curriculares Nacionais de Língua Portuguesa (PCNLP) do segundo ciclo do Ensino Fundamental (BRASIL, 1998), o desenvolvimento das competências leitora e escritora são essenciais à formação de cidadãos participativos. Deles destacamos:

\footnotetext{
O domínio da língua tem estreita relação com a possibilidade de plena participação social, pois é por meio dela que o homem se comunica, tem acesso à informação, expressa e defende pontos de vista, partilha ou constrói visões de mundo, produz conhecimento. Assim, um projeto educativo comprometido com a democratização social e cultural atribui à escola a função e a responsabilidade de garantir a todos os seus alunos 0 acesso aos saberes linguísticos necessários para o exercício da cidadania, direito inalienável de todos (BRASIL, 1998, p.16).
}

Em consonância com os PCN-LP, entendemos que é papel do professor de língua materna fornecer subsídios para que o aluno compreenda a função dos gêneros do discurso e seja capaz de atuar de forma crítica na sociedade em que vive, por meio do uso da linguagem oral ou escrita, sabendo informar-se, expor ideias e fatos, reivindicar direitos, fazer uma reclamação formal, persuadir seu interlocutor, entre outras atividades necessárias ao cidadão contemporâneo, tendo em vista sua inclusão social. Nessa perspectiva, o ensino de língua materna pode propiciar práticas de leitura, de escrita e de reflexões sobre a língua, como práticas 
sócio-históricas e abandonar as antigas práticas educativas mecânicas e descontextualizadas da realidade externa.

Tendo em vista o exposto, neste trabalho buscamos analisar as atividades voltadas à aprendizagem do gênero artigo de opinião contidas no material apostilado, fornecido aos alunos do $9^{\circ}$ ano da rede pública paulista, para verificarmos as atividades propostas aos alunos quanto ao que está prescrito no Currículo de Língua Portuguesa adotado pela Secretaria Estadual de Educação e para observar também sua correlação com as teorias que tratam do assunto. Buscamos conhecer, também, em que medida o material contribui para a aprendizagem desse gênero argumentativo.

A seleção do gênero discursivo artigo de opinião como foco desta pesquisa está relacionada à atual preocupação dos docentes no que diz respeito ao desempenho dos alunos do $9^{\circ}$ ano do Ensino Fundamental, nas atividades de produção de textos de opinião e no Sistema de Avaliação de Rendimento Escolar do Estado de São Paulo (SARESP). O SARESPé aplicado anualmente nas escolas estaduais pela Secretaria de Educação do Estado de São Paulo. Realizam as provas os alunos matriculados no $2^{\circ}, 3^{\circ} 5^{\circ}, 7^{\circ}$ e $9^{\circ}$ anos do Ensino Fundamental e da $3^{\text {a }}$ série do Ensino Médio. Uma das etapas da avaliação, tanto para o 9ำ ano do Ensino Fundamental quanto para as $3^{\text {a }}$ série do Médio, ${ }^{1}$ consiste em proposta da produção de um artigo de opinião.

O Relatório Pedagógico de Língua Portuguesa do SARESP 2012, elaborado pela Secretaria da Educação do estado de São Paulo, aponta que 396.647 alunos do 9a ano do Ensino Fundamental da rede estadual realizaram a prova do SARESP. $\mathrm{Na}$ redação, verificou-se que $62,6 \%$ desses alunos ainda não dominam as competências e habilidades escritoras para o ano escolar em que se encontram (SÃO PAULO, 2013, p. 13).

Para compreendermos esse dado preocupante, buscamos conhecer e explicitar de que modo o material apostilado utilizado nas escolas estaduais paulistas contribui para a aprendizagem do gênero artigo de opinião, observando o que é prescrito no Currículo estabelecido para a disciplina de língua portuguesa e

\footnotetext{
${ }^{1}$ Nesta pesquisa, optamos por centralizar nossa atenção no ensino fundamental, entendendo que a inclusão do ensino médio envolveria observações específicas, inclusive da ordem teóricometodológico quanto ao ensino de língua portuguesa.
} 
quais atividades são propostas nas apostilas dos alunos, para observar se a proposta teórica apresentada no Currículo Oficial é concretizada nas atividades apresentadas aos alunos pelo material didático.

\section{O ensino da produção textual}

Partimos, neste trabalho, da abordagem sociointeracionista que concebe 0 texto como "evento sociocomunicativo" em um processo interacional $(\mathrm{KOCH}$ e ELIAS, 2012, p.13). Nessa concepção, o texto não possui um significado prédeterminado; seu significado é construído, dialogicamente, através da interação entre os sujeitos envolvidos no processo comunicativo, não havendo, dessa forma, sujeito passivo. Entendemos, deste modo, que autor e leitor possuem um papel ativo na construção do texto.

Nesta pesquisa, a partir dos estudos de Bakhtin e o Círculo, concebemos o enunciado como um processo interativo que abrange ao mesmo tempo os aspectos verbais e o todo da situação comunicativa. Assim, o contexto sócio-histórico torna-se parte fundamental para a compreensão do processo de interação verbal que se dá a partir dos gêneros que circulam na sociedade.

A fim de interagirmos no meio social em que vivemos, necessitamos elaborar textos, sejam eles orais ou escritos. Para isso, não realizamos uma escolha aleatória. Essa seleção depende de fatores como o grau de formalidade ou informalidade da situação, os possíveis interlocutores, a finalidade da ação, as intenções e o próprio contexto sócio-histórico. Ao retomarmos o já consagrado ensaio "Os Gêneros do Discurso" (BAKHTIN, 1952-53), no qual o autor afirma que cada campo de utilização da língua elabora seus tipos de enunciados "relativamente estáveis", os quais ele denomina de "gêneros do discurso", podemos observar que, para cada situação comunicativa, tem-se fixado na memória um gênero discursivo adequado que atende às necessidades da comunicação pretendida (BAKHTIN, 2011[1952-53], p. 262).

A respeito do papel dos gêneros textuais no ensino, Marcuschi (2003) observa que um maior conhecimento dos gêneros é importante tanto para a produção como para a compreensão de textos. Segundo o autor, a escola deve ensinar não só a produção adequada dos gêneros, mas também seu uso adequado. 
O estudioso destaca que, além da oportunidade de proceder a um ensino de acordo com a proposta oficial dos Parâmetros Curriculares Nacionais (1998), o trabalho com os gêneros em sala de aula possibilita lidar com a língua "em seus mais diversos usos autênticos no dia a dia" (MARCUSCHI, 2003, p.35,36).

Diante do exposto, entendemos que, ao ensinar a produção textual nas aulas de língua materna, é necessário considerar a importância dos conhecimentos sobre os gêneros do discurso e o desenvolvimento das capacidades de selecionar e dominar o gênero adequado a cada esfera da comunicação.

O processo de produção textual ainda prevê outros procedimentos e mecanismos relevantes na produção de texto, dentre eles, a coesão e a coerência, que, segundo Fávero (1995), constituem fatores importantes de textualidade.

Ao produzir um texto, selecionam-se as informações e/ou opiniões que se deseja veicular e procede-se à organização dos enunciados. Para tanto, o produtor do texto necessita dispor de alguns mecanismos que estabeleçam relações entre os elementos textuais e auxiliem no desenvolvimento do texto. Esses mecanismos asseguram a coesão do texto. Já acoerência está relacionada ao sentido do texto à sua compreensão e interpretabilidade. Ambas estão diretamente ligadas, uma vez que os elementos coesivos são alguns dos fatores que possibilitam a construção do sentido de um texto, ou seja, de sua coerência (KOCH E TRAVAGLIA, 2014 [1990]).

Diante do exposto, reconhecemos, pois, a importância de se contemplar, no ensino, fatores linguísticos, cognitivos, intertextuais e sociointeracionais envolvidos no processo de produção textual. Acreditamos que o trabalho com os recursos de coesão e coerência em sala de aula pode possibilitar aos alunos uma maior compreensão do processo de composição de um texto e a importância desses elementos na construção da textualidade.

\section{Os textos argumentativos}

Neste trabalho, foi necessário nos reportarmos a uma das Teorias da Argumentação e nela nos aprofundarmos, para em seguida passarmos à discussão de sua aplicabilidade ao ensino e dos autores que a ela se dedicaram. Por isso, selecionamos a Nova Retórica, obra de Perelman e Olbrechts-Tyteca ([1958]2005), pelo fato de considerarmos seu destaque e relevância no atual cenário dos estudos 
da argumentação. Outra escolha teórica recai sobre Koch (1984) ${ }^{2}$ e está fundamentada na contribuição de seus estudos que contemplam perspectivas voltadas ao ensino da língua e à compreensão de textos.

Perelman e Olbrechts-Tyteca ([1958]2005) afirmam que, para argumentar, é necessário que se tenha apreço pela adesão do interlocutor e valorize seu consentimento. Ou seja, não basta argumentar, deve-se buscar a adesão do auditório conquistando-o por meio da persuasão ou do convencimento. Segundo os autores, em razão de a argumentação ter o objetivo de conquistar a adesão daqueles a quem se dirige, ela deve estar totalmente relacionada ao auditório que deseja influenciar. Conhecer aqueles que se pretende conquistar seria, pois, uma condição prévia para um discurso argumentativo eficaz e, tanto a seleção dos argumentos a serem utilizados, quanto a escolha da melhor estratégia argumentativa depende dos conhecimentos que se tem a respeito desse público. (PERELMAN e OLBRECHTS-TYTECA, [1958]2005).

Aquino (1997, p. 164), ao refletir sobre a importância do auditório na construção do discurso argumentativo, ressalta que "não há melhor maneira de se conseguir a adesão que não seja por intermédio de um acordo". A autora destaca que esses acordos são fundamentais para a argumentação e determinam não só as estratégias de seleção e apresentação dos argumentos, mas também as formas da argumentação.

Para Perelman e Olbrecht-Tyteca([1958]2005, p.50):

O objetivo de toda argumentação, como dissemos, é provocar ou aumentar a adesão dos espíritos às teses que se apresentam a seu assentimento: uma argumentação eficaz é a que consegue aumentar essa intensidade de adesão, de forma que se desencadeie nos ouvintes a ação pretendida (ação positiva ou abstenção) ou, pelo menos, crie neles uma disposição para a ação, que se manifestará no momento oportuno.

O objetivo da argumentação seria, pois, a conquista da adesão de um auditório; entretanto, essa conquista, muitas vezes, não ocorre tão facilmente ou até mesmo não ocorre. Por essa razão, Aquino (1997, p. 144) ressalta que a argumentação opera como reguladora de conflitos gerados pelo confronto de valores, muitas vezes incompatíveis, dos interlocutores. Além disso, segundo a autora, a ambiguidade seria outro fator que colabora para a criação de um ambiente conflituoso na argumentação uma vez que, ao buscar estabelecer um acordo com o

${ }^{2}$ Utilizamos a edição de 2011 do livro Argumentação e Linguagem. 
interlocutor, podem ocorrer divergências causadas pela pluralidade de significado das palavras.

Os estudiosos da Nova Retórica também se voltaram à questão da neutralidade do discurso. Para eles, "nada a esse respeito é mais arbitrário do que as distinções escolares entre discurso factual, neutro, descritivo, sentimental, emotivo" (2005, p.170). Asseverando com Benveniste (1966) que afirma a inexistência de discursos neutros, Koch (2011) também ressalta que a suposta neutralidade de alguns discursos é um mito, pois o discurso que se diz "neutro" ou ingênuo contém também uma ideologia.

Para exemplificar seu posicionamento, Koch (2011) aborda o processo de seleção lexical realizada pelo autor de um texto. Segundo a estudiosa, trata-se de um recurso de grande relevância, pois é através dele que se estabelecem as diversas relações presentes em um discurso (oposições, jogos de palavras, metáforas etc.). Por essa razão, a autora ressalta que o ensino da língua materna deve propiciar ao aluno o desenvolvimento de competências que o torne capaz de refletir e atuar, de forma crítica, na sociedade na qual está inserido.

As relações interpessoais que se estabelecem no momento da enunciação também contribuem para a construção do sentido de um texto. Nesta direção, Koch (2011) explica que o sentido não é algo preexistente à decodificação, mas, sim, constituído por ela. Segundo a estudiosa, será o interlocutor quem decidirá qual o significado que ele atribuirá ao enunciado, de acordo com as pistas linguísticas que permeiam todo o enunciado.

Diante das considerações desses estudiosos, entendemos que a seleção lexical é um importante elemento a ser considerado durante uma análise dos elementos argumentativos que compõem um texto, pois, certamente, apresenta pistas da construção nas quais o discurso argumentativo está estruturado.

A partir do que foi exposto, reconhecemos a importância do trabalho em sala de aula com os diversos níveis de significação (explícitas e implícitas) para, assim, capacitar os estudantes a lerem o que está escrito e o que está pressuposto ou subentendido no discurso, conforme a concepção de Ducrot (1987). 


\section{Os apostilados do sistema de ensino do estado de São Paulo}

Em 2008, a Secretaria de Educação do Estado de São Paulo (SEE-SP) implantou o programa São Paulo Faz Escola, uma nova proposta curricular para a rede de ensino pública. A ação tinha o objetivo de implantar um currículo pedagógico unificado para todas as disciplinas.

Em 2009, o Caderno do Aluno, específico por disciplinas, foi elaborado e distribuído aos estudantes de toda a rede estadual, assim como o material de apoio dos professores, e distribuía-se um volume para cada bimestre. O material permite que o aluno registre suas anotações, faça exercícios e desenvolva as habilidades do Currículo através da mediação dos professores.

O currículo oficial foi concluído em 2010 e contém um currículo para cada disciplina, com orientações, conteúdos previstos e competências e habilidades que devem ser alcançadas em cada ano/série dos ensinos Fundamental e Médio. $O$ documento está dividido em três grandes áreas: Ciências da Natureza, Ciências Humanas, Linguagem e Códigos, Matemática.

Em 2014, tanto os Cadernos do Professor, quanto os Cadernos do Aluno sofreram uma alteração em seus formatos: passaram a conter apenas dois volumes para cada disciplina, por série/ano, e passaram a ser entregues no início do ano, em fevereiro e, após as férias, no mês de agosto.

No tópico seguinte, descrevemos o apostilado Caderno do Aluno de língua Portuguesa do 9a ano, volume 1, corpus desta investigação, para, posteriormente, procedermos à análise das atividades propostas para o ensino do artigo de opinião.

\section{O Caderno do Aluno (CA) de Língua Portuguesa da $8^{a}$ série/ 9ªno}


Cada volume do Caderno do Aluno de Língua Portuguesa do Ensino Fundamental contém, em média, 10 módulos, as chamadas Situações de Aprendizagens (SA). Cada $S A$ propõe uma sequência de atividades baseadas no trabalho com um gênero ou tipologia textual. As $S A s$ contêm as seguintes atividades: Leitura e Análise de texto; Pesquisa em grupo (ou individual); Oralidade; Lição de casa; e $O$ que eu aprendi. Além dessas atividades, em alguns módulos também são apresentadas as seguintes propostas de atividades: Estudo da língua; Atividade em grupo; Produção escrita, Você aprendeu? E Para Saber Mais.

Após esta breve apresentação da implantação do sistema de ensino na rede de ensino paulista e da descrição do material apostilado da disciplina de Língua Portuguesa, destinado aos alunos das escolas paulistas, iniciamos, no próximo tópico, a análise do Currículo Oficial de Língua Portuguesa para o 9ำ ano do Ensino Fundamental quanto à orientação para o ensino da produção textual e da Situação de Aprendizagem 9 do Caderno do Aluno que contempla o ensino do artigo de opinião.

\section{Análise}

O documento que apresenta os Fundamentos para o ensino de Língua Portuguesa, do Currículo do Estado de São Paulo (CLP de agora em diante) ressalta que os conhecimentos linguísticos não devem ser reduzidos ao simples conhecimento da norma-padrão e destaca a necessidade de se considerar, no cotidiano escolar, o aspecto social da língua "que, como organismo vivo e pulsante, transforma-se a toda hora e relaciona os textos com o momento de produção e de leitura" (SÃO PAULO, 2012, p. 32).

Além disso, nesse documento, observamos a preocupação com 0 desenvolvimento da competência discursiva e com a promoção do letramento. Segundo os autores, "o centro da aula de Língua Portuguesa é o texto" que, compreendido em sentido semiótico, pode combinar diferentes linguagens, não apenas a verbal (SÃO PAULO, 2012, p. 32).

No documento, o texto é compreendido como uma unidade comunicativa completa, entretanto, aspectos como suas propriedades comunicativas e sociointeracionais, bem como suas relações com outros textos anteriormente 
proferidos (intertextualidade e interdiscursividade) não são indicadas como fundamentais para sua constituição. Constatamos, ainda, que não há referência aos dois elementos que determinam o texto como um enunciado concreto: a sua intenção e a realização dessa intenção, apontados por Bakhtin (2011[1959-61]) como propriedades relevantes em sua construção.

Ao contrário de Bakhtin (2011 [1959-61]), que reconhece a natureza dialógica dos textos com outros enunciados e concebe todo texto como sendo uma resposta a um discurso anterior, os autores do CLP salientam que um texto é uma produção individual moldada apenas pela esfera de utilização da língua. Nessa concepção, o gênero discursivo aparece como um modelo pronto, determinado pelas esferas sociais, produzidos por interlocutores para a comunicação.

Observamos também, que embora careça de uma discussão mais ajustada das propriedades discursivas dos textos, o CLP reconhece a importância de um ensino voltado ao trabalho do texto como centro do ensino e destaca a necessidade de se trabalhar com o texto nas diversas situações comunicativas.

O encaminhamento metodológico proposto pelo CLP reconhece a necessidade de se desenvolver a competência discursiva do aluno por meio de atividades que propiciem a interação social em diferentes situações comunicativas.

Antes de iniciarmos a análise da SA destinada ao ensino do artigo de opinião, apresentamos, a seguir,um quadro em que podemos observar como se distribuem, no $C L P$, as produções textuais propostas para o 9ํano do Ensino Fundamental:

Quadro 01: Produções textuais propostas ao $9^{\circ}$ ano do Ensino Fundamental, p.70-77

\begin{tabular}{|c|c|c|}
\hline $9^{\circ}$ ano & Tipologias & Gêneros \\
\hline 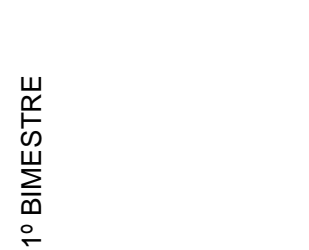 & Expositiva e Argumentativa & $\begin{array}{l}\text { Exposição oral. } \\
\text { Resenha crítica. } \\
\text { Debate regrado. }\end{array}$ \\
\hline 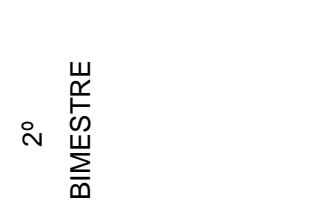 & Argumentativa & $\begin{array}{l}\text { Carta do leitor. } \\
\text { Artigo de opinião. }\end{array}$ \\
\hline
\end{tabular}




\begin{tabular}{|c|c|c|}
\hline 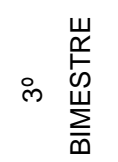 & Argumentativa & Texto de opinião \\
\hline 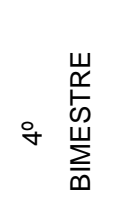 & Argumentativa & $\begin{array}{l}\text { Resumo. } \\
\text { Texto de opinião. }\end{array}$ \\
\hline
\end{tabular}

O material apostilado, que antes era enviado às escolas bimestralmente e continha um volume para cada bimestre, tanto para o professor quanto para o aluno, foi modificado e, em 2014, passou a conter apenas dois volumes, um para cada semestre. Como foi exposto anteriormente, o material, tanto o $C P$, quanto o $C A$, é organizado em Situações de Aprendizagem.

A partir da observação dos conteúdos propostos no primeiro volume da última série do Ensino Fundamental ( $9^{\circ}$ ano), verificamos que o trabalho com os textos argumentativos é iniciado na segunda $S A$ e continua nas demais através do trabalho com diferentes gêneros textuais argumentativos. Ao longo das $S A s$, são propostas leituras de textos variados sobre diversos temas como segurança, adolescência, racismo, entre outros, para constituírem a base temática das produções textuais dos alunos.

O trabalho com o gênero artigo de opinião aparece pela primeira vez na $9^{\mathrm{a}}$ Situação de Aprendizagem do primeiro volume do material apostilado do $9^{\circ}$ ano e é retomado no momento de sistematização dos conteúdos aprendidos, na última $S A$ do primeiro volume do $C A$, apenas como uma proposta de organização dos parágrafos argumentativos produzidos na $7^{\text {a }} S A$ do mesmo volume. Por esta razão, o foco da análise deste trabalho é a análise da Situação de Aprendizagem 9, intitulada "Produzindo um artigo de opinião".

\subsection{Situação de Aprendizagem 9 - "Produzindo um artigo de opinião"}

A Situação de Aprendizagem 9 é composta de dez páginas e está dividida em onze seções:1. "Oralidade"; 2. "Atividade em grupo"; 3. "Leitura e análise de texto"; 4. "Atividade em grupo"; 5. "Pesquisa em grupo"; 6. "Leitura e análise de texto"; 7. 
"Produção escrita"; 8. "Você aprendeu?"; 9. "Lição de casa"; 10. "Estudo da língua"; 11. "O que eu aprendi".

A $S A$ inicia-se com a seção Oralidade. Nela, propõe-se aos alunos que participem de uma roda de leitura, na qual o professor lerá alguns contos e poemas para que observem a fruição, e, em seguida, conversem sobre o que ouviram ou leram quanto aos temas tratados nos textos. Ao final da seção, há duas questões: a primeira, a respeito do posicionamento do eu lírico ou das personagens sobre os temas tratados, e a segunda, sobre a identificação dos alunos com suas posições ${ }^{3}$.

Posteriormente, na seção Atividade em grupo, propõem-se as seguintes questões:

Quadro 02: Transcrição das questões $a, b, c, d, e$ e, p.74

a) Em sua opinião, o Brasil é um país racista?
b) O que vocês acham desse tema?
c) O que sabem sobre racismo?
d) Já vivenciaram situações em que o racismo estivesse em foco?
e) Há alguma relação entre esse tema e os textos lidos na roda de leitura
anterior?

A atividade proposta permite que os alunos exponham seus conhecimentos, suas opiniões pessoais sobre o assunto (Racismo) e suas experiências. Além disso, auxilia os estudantes a observarem a relação entre o tema das questões e os textos lidos na atividade anterior. Em seguida, os alunos são instruídos a organizarem, em papel Kraft ou cartolina, um quadro onde devem ser preenchidas duas colunas com argumentos "coerentes" para cada uma das respostas dadas à questão: O Brasil é um país racista? Logo após, os alunos são orientados a apresentarem o quadro aos demais estudantes da classe, para que as respostas sejam comparadas. Ao final da atividade, há ainda três questões:

Quadro 03:Transcrição das questões $a, b$ e $c$, p. 74

a) Quais são as razões para considerar o Brasil um país racista?
b) Quais são as razões para não considerar o Brasil um país racista?
c) Qual das colunas apresentou mais argumentos em defesa de seu ponto de
vista?

\footnotetext{
${ }^{3}$ Nessa atividade, o professor é orientado a selecionar contos e poemas que abordem os temas preconceito ou racismo (CP, p. 95).
} 
Propõe-se, nessa atividade, que os alunos preencham o quadro com os argumentos baseados apenas na leitura de textos literários e nas experiências dos estudantes com o tema. Não são oferecidos aos alunos textos jornalísticos, históricos ou mesmo a opinião de outras pessoas, além do ponto de vista das personagens e dos alunos da classe. Elementos histórico-sociais dos fenômenos não são considerados no momento da construção dos argumentos.

Depois desse exercício, na seção Leitura e análise de texto, há dois artigos de opinião sobre o tema abordado na atividade anterior. O primeiro texto, O racismo como consequência, de Antonio Sérgio Alfredo Guimarães, apresenta a ideia de que o Brasil é um país racista. Já no segundo artigo de opinião, da autora Mary Lucy Murray Del Priore, intitulado O tempo não para, a autora defende que falar em racismo significaria retornar ao século XIX e não reconhecer as mudanças ocorridas nos últimos tempos. As referências apresentadas permitem verificar que ambos os textos foram publicados no jornal Folha de S. Paulo, da seção Tendências/Debates, em 18 de novembro de 2006.

Embora haja, ao final de cada texto, referências ao nome dos autores, título, local e data de publicação dos textos, a atividade não propicia aos alunos a compreensão do contexto de produção e de recepção dos artigos de opinião apresentados. Os elementos verbo-visuais presentes na publicação original não são mantidos no $C A$ e os demais elementos que compõem a página do jornal são ignorados. Assim, os alunos não são levados a reconhecer os textos como gêneros discursivos reais, intencionalmente produzidos para um público específico.

De acordo com Santos (2013, p.7), assim como em outros gêneros midiáticos, a temporalidade do artigo de opinião limita-se ao período de circulação do suporte no qual foi publicado e o espaço destinado a textos opinativos, em si, já apresentam muitas informações sobre a situação comunicativa. Essas informações são fundamentais para a compreensão do texto como um gênero discursivo e não podem ser desconsideradas no momento de sua interpretação, pois constituem uma parte significativa de sua forma composicional. Nessa direção, reconhecemos a importância de se recuperar a materialidade discursiva original dos textos trabalhados nos materiais didáticos destinados aos alunos.

Após as leituras dos dois artigos de opinião, propõe-se um exercício composto por sete questões que devem ser respondidas pelos estudantes, em seus 
cadernos. As questões propostas permitem que os alunos identifiquem a questão polêmica motivadora dos textos, o ponto de vista dos autores e os argumentos utilizados. Embora os estudantes sejam orientados a observar esses aspectos, a maior parte da atividade está voltada à expressão da opinião pessoal a respeito do tema. Em relação aos interlocutores dos textos lidos, não há informações a respeito do suporte onde os textos circularam. Dessa forma, sem os conhecimentos a respeito da ideologia ou do público-alvo do jornal não é possível recuperar as condições de produção, a esfera de circulação e de recepção dos artigos de opinião e, assim, compreender as vozes sociais que permeiam o discurso.

A seção seguinte, Atividade em grupo, apresenta um quadro-síntese para ser preenchido pelos alunos para a análise das características dos dois artigos de opinião lidos na atividade anterior:

Quadro04:Transcrição do quadro da Atividade em grupo, p.78 e 79

\begin{tabular}{|c|c|c|}
\hline Características do gênero & Texto 1 & Texto 2 \\
\hline $\begin{array}{l}\text { O autor trata de um tema } \\
\text { polêmico? }\end{array}$ & & \\
\hline $\begin{array}{l}\text { Há uma questão polêmica } \\
\text { definida. Qual? }\end{array}$ & & \\
\hline $\begin{array}{l}\text { O autor expõe sua opinião sobre } \\
\text { o tema de forma explícita. Em } \\
\text { que trecho? Transcreva-o. }\end{array}$ & & \\
\hline $\begin{array}{l}\text { Há marcas linguísticas que } \\
\text { indicam a presença do autor no } \\
\text { texto. Dê exemplos. }\end{array}$ & & \\
\hline $\begin{array}{l}\text { O autor apresenta diversos tipos } \\
\text { de recursos persuasivos } \\
\text { complementares, tais como: } \\
\text { argumento de autoridade, } \\
\text { argumento de provas concretas, } \\
\text { argumento com base em } \\
\text { consenso. } \\
\text { transcrevendo no espaço ao } \\
\text { lado, o uso de um desses } \\
\text { recursos. }\end{array}$ & & \\
\hline $\begin{array}{l}\text { Em que meio de comunicação os } \\
\text { dois artigos foram publicados? }\end{array}$ & & \\
\hline $\begin{array}{l}\text { O autor escreve em primeira ou } \\
\text { terceira pessoa? Anote um } \\
\text { trecho que confirme sua } \\
\text { resposta. }\end{array}$ & & \\
\hline
\end{tabular}


Nessa atividade, observamos que não há a introdução de novos elementos de análise textual. Tratam-se de questões voltadas apenas à identificação de elementos textuais como marcas de autoria, tipos de argumentos e suporte. Os efeitos de sentido construídos ao longo do texto por meio da seleção lexical e os fatores que compõem o gênero discursivo são ignorados no momento da análise dos textos. Amossy (2011) ressalta que todos os elementos que compõem a situação concreta de enunciação e o gênero do discurso no qual a fala está situada, seus objetivos, regras e restrições, devem ser examinados no momento da análise. Assim, é importante a elaboração de exercícios que contemplem esses elementos e auxiliem os estudantes a reconhecerem o papel de cada um deles na construção do discurso argumentativo.

Depois do quadro, na seção Pesquisa em grupo, os alunos são orientados a pesquisarem na internet e/ou no livro didático o conceito de intertextualidade e anotarem no caderno pelo menos duas definições encontradas.

Posteriormente, apresenta-se novamente a seção Leitura e análise de texto. Nela, propõe-se aos estudantes que ouçam a música $O$ tempo não para, de Cazuza e respondam a algumas questões. Ao contrário do que está prescrito no $C L P$, a respeito da centralidade do texto no ensino da Língua Portuguesa, essa atividade propõe a aprendizagem de um conhecimento essencial para a compreensão textual por meio de uma pesquisa extraclasse descontextualizada e sem relação com a língua em uso. As questões sugeridas possibilitam uma reflexão sobre a relação que existe entre o texto de Pietro e a música de Cazuza, contudo, o conceito de intertextualidade é abordado nesse exercício sem a profundidade necessária e, assim, de modo restrito, considerado como um fenômeno isolado e explícito, ignorando a interdiscursividade que, muitas vezes, está implícita e requer que os leitores realizem inferências para compreendê-la.

Koch e Elias (2012, p. 125) ressaltam a importância, no ensino da produção de textos, de "chamar a atenção dos alunos para o fenômeno da intertextualidade". Para as autoras, não se trata apenas de estabelecer relações entre os textos, como ocorre na atividade analisada, mas, principalmente, da compreensão do modo como elas se constroem, quais seus objetivos e o do modo pelo qual se posiciona frente aos textos com os quais dialogam. Entendemos, assim, que esse tipo de trabalho 
em sala de aula pode auxiliar os estudantes a observarem como se dá a construção da intertextualidade e a utilizarem os mesmos recursos em suas futuras produções de texto.

Em Produção escrita, os alunos são orientados a escolherem, em grupos, um tema de uma lista apresentada pelo professor sobre os quais devem produzir um texto. Cada tema apresentará uma questão polêmica e os alunos são instruídos a escolherem e pesquisarem sobre os temas de seu interesse, a fim de ampliarem seu repertório sobre o assunto e organizarem os argumentos a serem utilizados no texto. Após a pesquisa, os grupos devem responder à questão formulada, produzindo dois artigos de opinião divergentes: um defendendo e um refutando o tema proposto. Para tanto, são apresentados alguns passos que devem ser seguidos pelos estudantes:

Quadro 05: Transcrição das orientações aos alunos, p. 81:

a) preparar um quadro que apresente uma coluna com argumentos a favor e uma
coluna com argumentos contrários;
b) dividir o grupo em subgrupos no momento da composição da escrita do artigo
de opinião para que cada equipe possa se concentrar em apenas um dos lados
da questão ( a favor ou contra);
c) cada subgrupo deve se encarregar de escrever o artigo, tomando o cuidado de
planejar, textualizar, revisar, reelaborar;
d) ao terminar e antes de apresentar os artigos a toda a classe, os subgrupos
devem comparar os dois artigos que fizeram, observando se, de fato,
conseguiram manter coerência na defesa de seu ponto de vista ao selecionar
argumentos pertinentes.

Podemos observar que a principal atividade da $S A$, destinada ao ensino da produção do artigo de opinião, propõe que a escrita seja realizada em grupo. Não há uma situação comunicativa real que estimule os alunos a produzirem seus textos e os auxilie na construção do texto, considerando os conhecimentos sobre os possíveis interlocutores e o seu contexto de recepção. A partir do exposto, entendemos que, nessa atividade, os estudantes são orientados a produzirem um texto que se assemelha à dissertação escolar, pois não há o reconhecimento dos aspectos discursivos do gênero artigo de opinião. Dessa forma, mais uma vez, o exercício contradiz o que é prescrito aos docentes no CLP: 
Alguém, com seu trabalho físico e mental, produz um texto em determinado tempo e espaço. Esse texto será interpretado por outro indivíduo, com uma personalidade específica, que pode ou não estar nos mesmos tempo e espaço do produtor. A esse fato que leva em conta esses três eixos (tempo, espaço, indivíduo) na produção/recepção textual denominamos enunciação (SÃO PAULO, 2012, p 33,34).

Além disso, no $C A$, propõe-se aos grupos que se dividam e produzam dois artigos de opinião, um contra e outro em defesa da questão polêmica. Observamos que os fatores de textualidade responsáveis pela construção da coerência textual não são trabalhados ao longo da atividade. Entendemos que os termos "textualizar", "revisar", "reelaborar" e "coerência" (SÃO PAULO, 2014, p. 81) não são abordados no exercício de modo suficiente e não se configuram orientações significativas para a composição do texto.

Como sabemos, a coerência de um texto é decorrente de múltiplos fatores. Koch e Travaglia (2014, [1990] p.71-100), ao retomarem os estudos de Beaugrande e Dressler (1981), apresentam alguns fatores responsáveis pela construção da coerência textual: elementos linguísticos; conhecimento de mundo; inferências; informatividade; focalização, intencionalidade e aceitabilidade, entre outros. Apesar de propor aos alunos que verifiquem se conseguiram manter a coerência na defesa do ponto de vista por meio da utilização de argumentos pertinentes, o exercício proposto no $C A$ não contempla o ensino ou mesmo a retomada desses fatores responsáveis pela construção da coerência e, assim, não contribui para o desenvolvimento da aprendizagem dos estudantes.

O trabalho com os recursos de coesão e coerência em sala de aula pode possibilitar aos alunos uma maior compreensão do processo de composição de um texto, mostrando-Ihes a importância desses elementos na construção da textualidade. Deste modo, ao ignorar esses recursos no momento de ensino da leitura e da produção de texto, o material didático revela um descompasso entre as teorias linguísticas sobre o assunto e o ensino proposto em sala de aula.

O artigo de opinião é um gênero escrito pertencente à esfera jornalística em que se defende uma tese sobre uma questão polêmica e tem por objetivo persuadir seu interlocutor e ajudá-lo a construir sua opinião sobre o fato ou modificá-la. De acordo com Perelman e Olbrechts-Tyteca ([1958]2005), em razão de a argumentação ter o objetivo de conquistar a adesão daqueles a quem se dirige, ela deve estar totalmente relacionada ao auditório que deseja influenciar, ou seja, os conhecimentos sobre os interlocutores são fundamentais para a construção de 
discurso argumentativo eficaz. Nessa direção, observamos que há divergências entre as teorias que tratam do assunto e as atividades efetivamente propostas em sala de aula, uma vez que, nessa atividade, os alunos não sabem quem serão os possíveis interlocutores de seus textos e são orientados a produzirem os textos apenas como um exercício mecânico.

Em seguida, ainda na mesma seção, orienta-se que troquem os artigos com os demais alunos da sala, mas sem a preocupação de realizar correções ou intervenções. Após essa etapa, solicita-se que eles entreguem os textos ao professor, para que sejam avaliados e recebam as intervenções necessárias. Ao final desta etapa, os alunos devem reformular os artigos de acordo com as orientações do professor e, se a escola possuir um laboratório de informática, cada grupo deve montar um blog para a publicação dos textos. Caso não seja possível, de acordo com o CA, os artigos podem ser afixados no mural da escola.

Na seção Você aprendeu?, propõe-se aos estudantes que avaliem oralmente como foi o processo de escrita do artigo de opinião, observando como se deram as discussões sobre os temas, a organização dos argumentos e as dúvidas que surgiram.

Na seção Lição de casa, há um exercício no qual os alunos devem responder $\mathrm{V}$ (verdadeiro) ou $\mathrm{F}$ (falso) para algumas questões referentes à estrutura e características do gênero artigo de opinião. Observamos, nessa seção, que o exercício apresentado contempla algumas características do gênero artigo de opinião. Porém, além de serem apresentadas apenas ao final da $S A$, trazem concepções do gênero como um modelo de texto, desconsiderando a dimensão discursiva e dialógica do artigo de opinião. Entendemos que as características do gênero (elementos composicionais, tema e estilo) e suas propriedades discursivas deveriam ser trabalhadas por meio da leitura de diversos artigos de opinião publicados em jornais e revistas (impressos ou online), preservando a materialidade original de cada texto e recuperando seus contextos de produção e recepção.

Ao final da SA, propõe-se que se faça uma pesquisa no livro didático ou em uma gramática sobre as figuras de linguagem e que suas definições sejam anotadas no caderno. Além disso, os estudantes são orientados a realizarem exercícios de sistematização indicados pelo professor e a anotarem as possíveis dúvidas. Em 
seguida, com base no estudo das orações coordenadas, também é proposto que respondam algumas questões teóricas.

Novamente, o exercício proposto apresenta-se como um retorno às práticas tradicionais de ensino da língua, desvinculada de sua função sociointeracionista. Atividades como essa revelam uma concepção da gramática da língua como um elemento formal que deve ser memorizado, sem reflexão. Finalmente, a última seção, Eu aprendi, propõe que os alunos escrevam no CA uma síntese dos conteúdos que aprenderam ao longo da $S A$.

\section{Conclusão}

Neste trabalho, analisamos os encaminhamentos das atividades voltadas ao ensino da produção do gênero artigo de opinião, contidas no material apostilado que compõe o sistema de ensino adotado nas escolas públicas do Estado de São Paulo. Desse modo, para conhecer em que medida as atividades propostas contribuem para a aprendizagem desse gênero argumentativo, buscamos verificar se as propostas de produção textual encontradas no Caderno do aluno ( $C A)$ são coerentes com as prescrições oferecidas aos docentes no Currículo de Língua Portuguesa $(C L P)$ e com as teorias que tratam do assunto.

$\mathrm{Na}$ análise das atividades destinadas à leitura de artigos de opinião, verificamos que as questões propostas não auxiliam os alunos na construção da criticidade bem como não retomam elementos discursivos fundamentais para a compreensão dos textos como suas esferas de circulação, produção e recepção. Assim, acreditamos que as atividades de leituras contidas no material mereceriam ser mais aprofundadas e direcionadas à observação dos aspectos linguísticodiscursivos dos textos, tendo em vista que, em nossas análises, encontramos atividades voltadas somente à extração de informações explícitas do texto e à identificação de elementos estruturais do gênero.

No que tange às atividades de produção escrita do artigo de opinião que foram analisadas, podemos dizer que as propostas e orientações oferecidas aos estudantes apresentam uma linguagem prescritiva e autoritária e são apresentadas como se os conceitos referentes ao gênero discursivo tivessem sido trabalhados ao longo da Situação de Aprendizagem ( $S A$ ) ou em unidades anteriores. Dessa forma, 
as instruções dos exercícios apresentam orientações vagas que não auxiliam os alunos na construção linguístico-discursiva do seu texto.

Verificamos, também, que além de não serem orientados a respeito do contexto de produção e circulação dos textos que irão produzir, os estudantes são levados a produzirem seus textos de forma mecânica e segmentada.

A análise dos encaminhamentos propostos para o ensino da produção do artigo de opinião nos permite dizer que a SA apresentada no CA não possibilita que os alunos vivenciem a escrita argumentativa como prática social, mas sim como um exercício escolar descontextualizado. Dessa forma, entendemos que o material apostilado oferecido aos alunos do $9^{\circ}$ ano da rede estadual paulista não contribui para uma aprendizagem significativa da produção do artigo de opinião.

Não pretendemos, com este trabalho, esgotar as possibilidades de análise dos encaminhamentos propostos para o ensino da produção do artigo de opinião. Enfatizamos a importância de estudos voltados ao ensino da produção textual e a necessidade de pesquisas a respeito do trabalho com os gêneros argumentativos em sala de aula.

\section{Referências}

AMOSSY, R. Argumentação e Análise do Discurso: Perspectivas teóricas e recortes disciplinares. Tradução Eduardo Lopes Piris e Moisés Olímpio Ferreira. EID\&A: Revista Eletrônica de Estudos Integrados em Discurso e Argumentação. Ilhéus, n.1, p.129-144, Nov. 2011.

AQUINO, Z. G. O. Conversação e conflito: um estudo das estratégias discursivas em interações polêmicas. Tese (Doutorado). Faculdade de Filosofia, Letras e Ciências Humanas, Universidade de São Paulo, São Paulo, 1997.

BAKHTIN, M. M. (VOLOCHINOV, V. N.). Marxismo e filosofia da linguagem: problemas fundamentais do método sociológico na ciência da linguagem. Tradução Michel Lahud e YaraFrateschi Vieira. São Paulo: Hucitec, 12. ed.,2006 [1929].

BAKHTIN, M. M.. O problema do texto na linguística, na filologia e em outras ciências humanas: uma experiência de análise filosófica (1959-61). In:

Estética da Criação Verbal.Tradução Paulo Bezerra. São Paulo: Martins Fontes, 6. ed., 2011, p. 307-335.

. Os Gêneros do Discurso (1952-53). In:

Estética da Criação

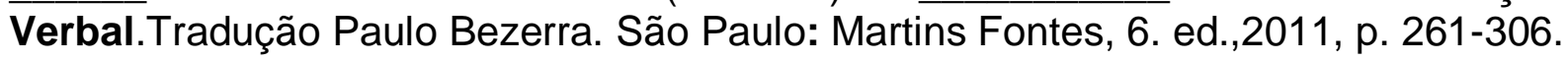


BEAUGRANDE, R. A.; DRESSLER, W. U. Introduction to text linguistics.London/ New York: Longman, 1981.

BRASIL, Parâmetros Curriculares Nacionais: Introdução aos Parâmetros, Brasília: MEC/SEF, 1997.

Parâmetros Curriculares Nacionais: Terceiro e quarto ciclos do ensino fundamental: Língua Portuguesa/Secretaria de Educação Fundamental. Brasília: MEC/SEF, 1998.

DUCROT, O. O dizer e o dito. Campinas: Pontes, 1987.

KOCH, I. V. Argumentação e Linguagem. São Paulo: Cortez, 2011 [1984].

A coesão textual. São Paulo: Contexto, 22.ed., 2014.

.O texto e a construção dos sentidos. São Paulo: Contexto, 10. ed., 2013.

$\mathrm{KOCH}$, I. V.; ELIAS, V. M. Ler e compreender: os sentidos do texto. 3.ed. São Paulo: Contexto, 2013.

$\mathrm{KOCH}$, I. V.; ELIAS, V. M.. Ler e escrever: estratégias de produção textual. 2.ed. São Paulo: Contexto, 2012.

$\mathrm{KOCH}$, I. V.; TRAVAGLIA, L. C. A coerência textual. 18 ed. $3^{\underline{a}}$ reimpressão. São Paulo: Contexto, 2014.

MARCUSCHI, L. A. Linguística de texto: o que é e como se faz. Recife: Universidade Federal de Pernambuco, Série Debates, 1, 1983.

Cortez, 2003.

Da fala para a escrita: atividade de retextualização. 4. ed . São Paulo,

PAES, M. V.; RAMOS, G. P. O programa "São Paulo faz escola" e seu modelo de gestão tutelada. Comunicações, Piracicaba, ano 21, n. 2, p. 53-66, jul./dez. 2014.

OLBRECHTS-TYTECA, L. Tratado da argumentação: a nova retórica. Tradução Maria Ermantina de Almeida de Almeida Prado Galvão. São Paulo: Martins Fontes, 2.ed.,[1958]2005.

SANTOS, I. B. A. Projetos de letramento: ressignificação da prática docente. In: OLIVEIRA, M.S.; KLEIMAN, A.B. (orgs). Letramentos múltiplos: agentes práticas e representações. Natal: EDUFRN, 2008, p.1-218.

. BRASIL, Secretaria do Estado de São Paulo. Caderno do Aluno: Língua Portuguesa, Ensino Fundamental, 8 ${ }^{\underline{a}}$ série/9a ano, volume 1.Coordenação geral: Maria Inês Fini, coordenação da área: Alice Vieira. Nova Edição. São Paulo: SEE,2014b.

BRASIL, Secretaria do Estado de São Paulo. Currículo do Estado de São Paulo: Linguagens códigos e suas tecnologias. Coordenação geral: Maria Inês Fini, coordenação da área: Alice Vieira. São Paulo: SEE, 2012. 
Artigo recebido em: 15 de outubro de 2015

Artigo aprovado em: 15 de junho de 2016

Sobre a autora:

Sílvia Mamede de Carvalho é Mestra em Letras pela Universidade de São Paulo (USP) (PROFLETRAS), em 2015. Possui graduação em Letras pela Universidade Estadual Paulista Júlio de Mesquita Filho, UNESP, (2009). Atualmente é professora efetiva de Língua Portuguesa da Secretaria da Educação do Estado de São Paulo, na cidade de Marília. Pesquisa de Mestrado: O ensino do artigo de opinião - das teorias às atividades didáticas dos apostilados da rede pública paulista; orientadora: Professora Doutora Zilda Gaspar Oliveira de Aquino. (Bolsista CAPES) 